\title{
Publication rates of podium presentations at the annual South African Orthopaedic Association Congress from 2010 to 2015
}

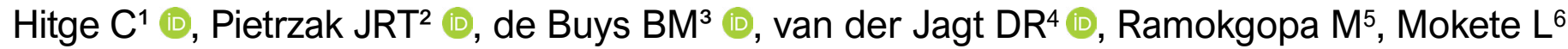

1 MBBCh(Wits), BSc(Wits); Registrar, Department of Orthopaedic Surgery, University of the Witwatersrand, Johannesburg

2 FC Orth(SA), MBBCh(Wits); Consultant, Arthroplasty unit, Department of Orthopaedic Surgery, University of the Witwatersrand, Charlotte Maxeke Johannesburg Academic Hospital

3 MBBCh(Wits), BSc(Med)(Hons); Registrar, Department of Orthopaedic Surgery, University of the Witwatersrand

4 FC Orth(SA), MBBCh(Wits); Professor, University of the Witwatersrand, Charlotte Maxeke Johannesburg Academic Hospital

5 FCS(Orth)SA, MBChB(UKZN); Head of Orthopaedic Department, University of the Witwatersrand, Chris Hani Baragwanath Academic Hospital

6 FRCS(Edin), FRCS(Eng), FC Orth(SA), MBChB(UCT); Senior Consultant, Department of Orthopaedic Surgery, University of the Witwatersrand, Charlotte Maxeke Johannesburg Academic Hospital

Corresponding author: Dr Curran Hitge, Department of Orthopaedic Surgery, Charlotte Maxeke Johannesburg Academic Hospital, University of the Witwatersrand, Jubilee Road, Parktown, Johannesburg, 2196, South Africa; tel: +2720714006969, email: cuz.hitge@gmail.com

\begin{abstract}
Background: International literature shows a discrepancy between presentations at annual general orthopaedic meetings and subsequent publication. The aim of this study was to determine the publication rate of manuscripts presented as podium presentations at the South African Orthopaedic Congress (SAOC) from 2010 to 2015.

Materials and methods: All abstracts accepted as podium presentations at the SAOC from years 2010 to 2015 were identified from the archives of the South African Orthopaedic Society (SAOA). Abstract titles and authors were searched using search engines looking for all published manuscripts. The presentations were cross-referenced with publications and the conversion ratio from presentation to publication was compared to international results. Sub-analyses included orthopaedic subspecialty performance and publication rates and the types of research conducted. Record was also made of each publication's journal impact factor and date of publication. Results: A total of 445 abstracts were accepted for podium presentation by the SAOC from 2010 to 2015 . Of these, 70 (15.7\%) were published in peer-reviewed journals. The mean time from presentation to publication was 16 months with an average journal impact factor of 1.29. Orthopaedic Trauma (21.67\%) and Foot and Ankle Surgery subspecialties (21\%) were responsible for the most publications in general. The South African Orthopaedic Journal (44.29\%), Strategies in Trauma and Limb Reconstruction (6.7\%) and the Injury Journal (6.7\%) were the three most common publishing journals.

Conclusion: A lower conversion rate from podium presentation at SAOC to publication exists compared to similar published international findings. A poor publication rate was highlighted across all orthopaedic subdisciplines. Half of the publications appeared only in local journals, with just over $8 \%$ of presentations reaching international publication. The results suggest there is a need to identify barriers to publication among South African orthopaedic surgeons.
\end{abstract}

\section{Level of evidence: Level 4}

Key words: publication rate, South African Orthopaedic Association, South African Orthopaedic Congress

Citation: Hitge C, Pietrzak JRT, de Buys BM, van der Jagt DR, Ramokgopa M, Mokete L. Publication rates of podium presentations at the annual South African Orthopaedic Association Congress from 2010 to 2015. SA Orthop J 2019;18(3):58-62. http://dx.doi.org/10.17159/2309-8309/2019/v18n3a7

Editor: Prof LC Marais, University of KwaZulu-Natal, Durban, South Africa

Received: February 2018

Accepted: May 2019

Published: August 2019

Copyright: @ 2019 Hitge C, et al. This is an open-access article distributed under the terms of the Creative Commons Attribution Licence, which permits unrestricted use, distribution and reproduction in any medium, provided the original author and source are credited.

Funding: No funding was required in the preparation of this paper.

Conflict of interest: All authors declare that there are no conflicts of interest regarding this research. 


\section{Introduction}

The various medical disciplines globally have annual association meetings which represent an anticipated event in the academic calendar. These meetings generally consist of a programme that includes lectures or instructional courses, as well as presentations of the latest research and clinical evidence from a given field. It has been summated that the quality of a presentation and by extension the quality of an orthopaedic meeting in general, can partly be determined by the quality of research presented at these meetings. ${ }^{1-3}$

Research at annual general meetings is typically presented in two main formats: podium or poster presentations. Several studies have attempted to assess the quality of research produced at annual meetings. ${ }^{1-5}$ Podium presentations have been shown to be more than two or three times more likely to be published than poster presentations. ${ }^{1,5,6}$ Quality of presentations may be evaluated by determining the subsequent publication rate in peer-reviewed journals. ${ }^{4}$

The American Academy of Orthopaedic Surgeons' annual general meeting is widely recognised as the gold standard in terms of quality of meeting with $58 \%$ of presentations at this congress proceeding to publication. ${ }^{2,7}$ Developed countries, especially those from North America and the European Union, have been shown to produce the most literature in any given medical field. ${ }^{8}$ This is believed to be due to more access to appropriate funding for research projects, more competition within the field, and improved proficiency in the English language. ${ }^{8}$ As such, research coming out of these unions is more likely to go on to publication than any other centre around the world. ${ }^{3}$ In addition, it has been shown that most presentations are published within four years of presentation, and the mean time to publication has been shown to be $15-25$ months. ${ }^{1,4,9}$

The aim of this study was to assess the conversion rate from all abstracts accepted for podium presentations between 2010 and 2015 at the South African Orthopaedic Association (SAOA) annual congress into subsequent manuscripts and then on to full publication. Moreover, the study looked at each orthopaedic subdiscipline and assessed the rate of publication of each following podium presentation. The study also aimed to evaluate the type of journals that published the articles, the impact factor of these journals and, by inference, the quality of research.

\section{Methodology}

The SAOA was contacted directly and the release of the congress brochures for the SAOA meetings from 2010 to 2015 were requested. Only podium presentations were captured, and all poster and instructional course presentations were excluded. A six-year time frame was chosen to collect an adequate sample size, as well as to allow sufficient time for publication, in accordance with published literature.1,4,9

Abstract titles of the presentations were entered into different search engines to evaluate if the presentation had subsequently been converted into a formal manuscript and gone on to publication in a peer-reviewed journal. Search engines included Pubmed, Google Scholar, Google, Scielo and EMBASE. If no matches were found, the authorship as well as title key words were used as search inputs in an attempt to find a different link to the title of the publication.

If the author in question was responsible for other research publications, an attempt was made to enter in key words to filter through other publications to find relevant matches. If no hits were achieved after four Pubmed searches, assumption of non-publication was made, an assumption that is supported by Schoenfeld et al. ${ }^{10}$
If a hit was achieved on one platform, the process was still repeated on all other platforms to ensure all journal publications were found. All journal publications were recorded and tallied to establish which journals were most popular. Successful publications were divided into international and local South African journal publications. The presentation-to-publication conversion rate was compared to international experience.

The abstract titles were divided into subspecialties by assessing the title as well as the authors involved. The division into eight subspecialties was made based on recognised subspecialties in the South African context and included Arthroplasty, Upper Limb and Hands, Trauma, Paediatrics, Spine, Foot and Ankle, Tumour and Sepsis, and Sports and Knee. The subspecialties were analysed both in terms of the quantity of research presented as well as the quality, determined by assessing their subsequent publication rates. Furthermore, presentations were separated into three categories of research as done by Marsland et al. ${ }^{2}$ These included: Clinical studies or Case Series; Basic Science or Biomechanical; and Audit, Miscellaneous or Educational. ${ }^{2}$ The number of publications in each category were recorded and results compared to literature.

For each presentation, the time of presentation from the date of the congress was recorded. If the presentation went on to publication, the month and year of publication was recorded. The date of publication was used rather than the date of journal acceptance. ${ }^{4}$ This ultimately provided a time taken to publication for each presentation. Articles that were published prior to the year of presentation were excluded from the calculation of time to presentation but publications from earlier in the year of presentation were still included.

Each journal was evaluated for its 2018 recorded impact factor score as provided by the Researchgate web portal. This is a marker of the scientific influence of a journal. A score of zero was allocated to the journal if no impact factor score was found. Local journals were excluded from the calculation to avoid skewing of the results as the South African Orthopaedic Journal (SAOJ) did not feature on the portal used.

\section{Results}

A total of 445 podium presentations were presented at the annual SAOA Congress between 2010 and 2015 (Figure 1) with a total of $70(15.7 \%)$ podium presentations going on to publication in peerreviewed journals.

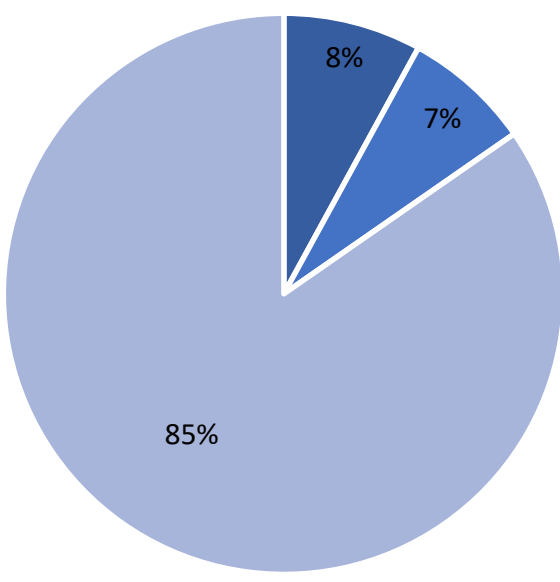

- International Journals - Local Journals $\quad$ Not Published

Figure 1. Comparison between total number of podium presentations and those that went on to international or local publication (2010-2015) 
120

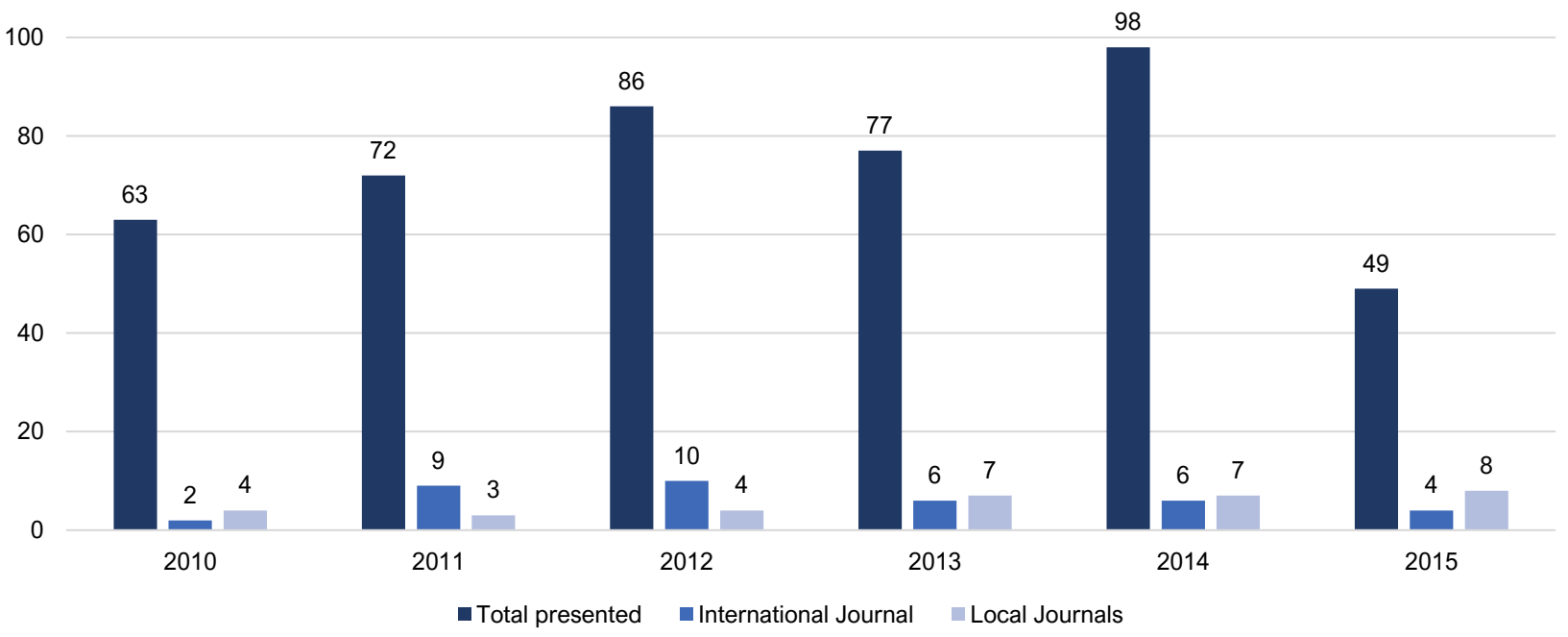

Figure 2. Comparison between number of total podium presentations (dark blue) and the subsequent number of international (blue) and local journal publications (light blue) in each year of study

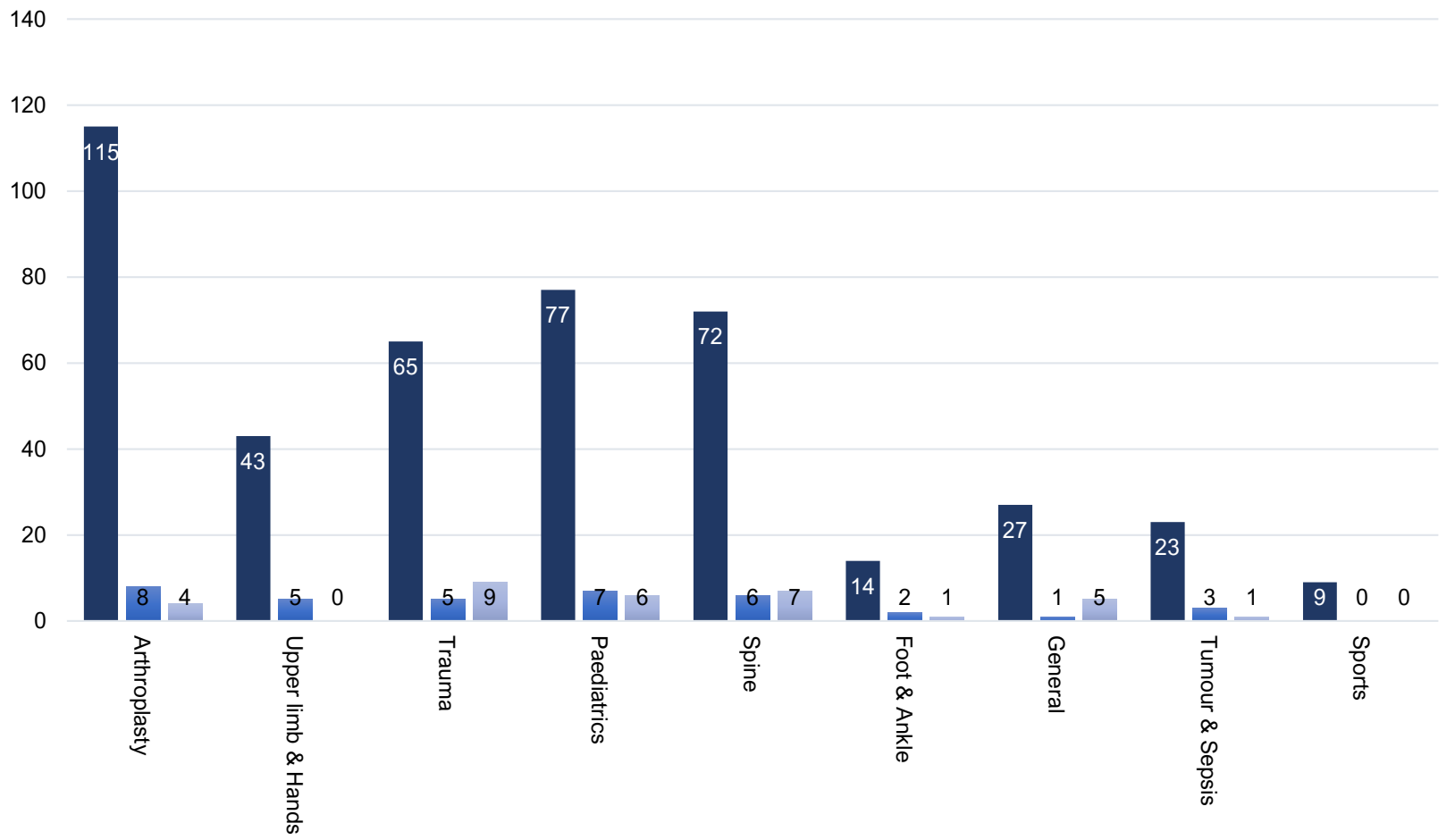

Figure 3. Subspecialty comparison looking at the number of total podium presentations (dark blue) and subsequent international (blue) and local (light blue) publications (2010-2015)

Of these, 37 (8.31\%) presentations were published in international journals and $33(7.42 \%)$ were published in local South African journals (Figures 1 and 2).

Analysing each subspecialty showed that Arthroplasty had the most podium presentations at $115(25.84 \%)$ and from this eight (7\%) international publications and four (3.5\%) local publications were derived. Orthopaedic Trauma and Foot and Ankle were the subspecialties with the highest publication rates at $21.67 \%$ and $21 \%$ respectively (Figure 3 ). The most internationally published subspecialty was Foot and Ankle at $14 \%$ followed by Tumour and Sepsis with $13 \%$ and then Upper Limb and Hands with $12 \%$. There were 27 podium presentations that did not fit an individual specialty, of which one $(3.7 \%)$ was published in an international journal and five $(18.52 \%)$ were published in local journals.
There was a total of 25 journals that published manuscripts from the podium presentations examined in this study. The SAOJ was the most common journal wherein presentations were published, with $31(44.29 \%)$ of the publications. The most common international peer-reviewed journals that received podium presentation publications were Injury and Strategies in Trauma and Limb Reconstruction, with four (6.67\%) entries each. There were also three (5\%) publications in the Journal of Hand Surgery and the Journal of Bone and Joint Surgery (JBJS).

Of the 445 podium presentations, 165 were based on clinical studies or case series, 140 had a basic science or biomechanical base and 140 were audits, educational or miscellaneous. Forty-one per cent of publications were clinical studies or case series, while $27 \%$ were basic science. 


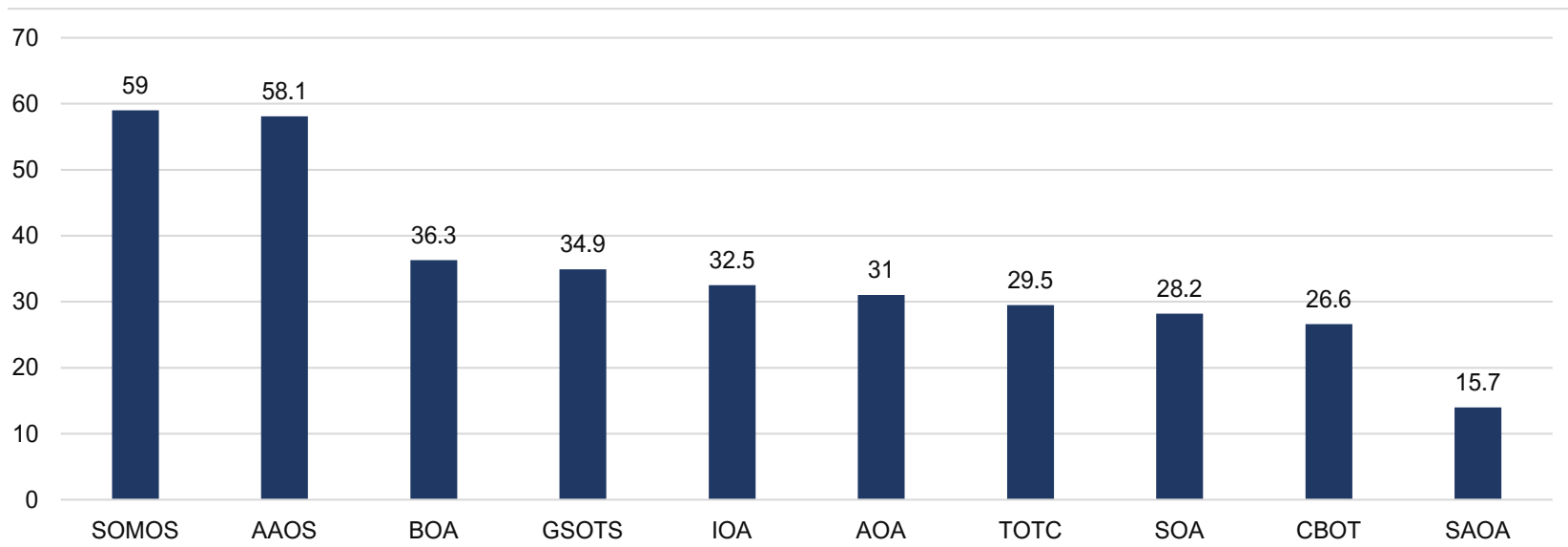

Figure 4. Comparison of overall documented publication rates (in \%) from presentations at different international conferences

American Academy of Orthopaedic Surgeons (AAOS); Australian Orthopaedic Association (AOA); British Orthopaedic Association (BOA); Congresso Brasileiro de Ortopedia (CBOT); German Society of Orthopaedics and Traumatology Congress (GSOTS); Irish Orthopaedic Association (IOA); South African Orthopaedic Association (SAOA) and Singapore Orthopaedic Association (SOA); Society of Military Orthopaedic Surgeons (SOMOS); Turkish Orthopaedics and Traumatology Congress (TOTC)

The mean time from presentation to publication was 16 months (range from six months prior to presentation to seven years post presentation). There were seven presentations that were excluded due to publication occurring prior to the year of SAOC presentation. The impact factors as determined by the Researchgate ranged from 0.25 to 3.06 with an average of 1.29 .

\section{Discussion}

It was found that $15.7 \%$ of podium presentations at the SAOC between 2010 and 2015 went on to publication. Of this, $7.4 \%$ of the presentations were published locally in South African journals with $8.3 \%$ of presentations being published in international journals. These findings correlate unfavourably with international experience where publication rates range from 26.6 to $59 \%$ (Figure 4). ${ }^{1,4}$ This highlights a significant lack of progression to publication and raises a number of important questions about barriers to publication for research in South Africa.

The results above suggest that there is a lack of progression to publication of research that is conducted within the South African orthopaedic circuit. Investigation into the possible sources of this shortfall may provide valuable insight and ultimately create solutions to the poor publication rates in South Africa. Peerreviewed journals have rigorous criteria to meet in order to qualify for publication; these criteria are largely more stringent than that required for podium presentations at general meetings and as such research presented at the SAOC may not be accepted for publication. ${ }^{1,4}$

Further barriers to publication have also been cited and include the following:

- Lack of time for authors to write up their research

- Poor communication between authors and co-authors

- Deficiency of senior mentorship in preparation of a manuscript

- Deficit of support from the institution, financially and logistically. $2,4,11$

It has also been hypothesised that because presentations at the $S A O C$ is a requirement for most orthopaedic surgeons in training, there is an initial drive to start research in order to write an abstract that would qualify for a general meeting. Once the abstract is accepted however, the motivation to complete the research in the form of a journal submission may be lost. Furthermore, it may be worth assessing how many presentations have gained ethical clearance prior to presentation, as this would later be required for publication in an accredited journal. The level of experience of the author may also have a significant impact on the publication rate. Experienced authors with a history of achieving publications will have a clearer idea of requirements for publication and therefore have directed research aims.

On 1 January 2011, a compulsory Masters in Medicine (MMed) was introduced to all specialist training programmes in South Africa by the Health Professions Council of South Africa. This was done in an attempt to enhance the quality of specialists in the respective fields and expose students to research. ${ }^{11}$

This MMed programme may therefore play a role in increasing subsequent publication rates of papers presented at the annual general meetings in future and will ensure that all candidates are exposed to research and research methodology. Chan et al. revealed that students not allocated a research block reported publication rates of $8 \%$. This was in comparison with $29 \%$ publication rates from students who were given dedicated research leave. ${ }^{11}$ It can be postulated that sufficient support and opportunity afforded to training students may enhance subsequent research output.

The low conversion rates may be a reflection of the scientific quality of the SAOC.

High quality meetings may be defined as those from which a large proportion of presented research has gone on to publication, ${ }^{4}$ whereas a lower publication rate may represent deficiencies in the quality of the meeting.

Subspecialty performance review shows a general lack of conversion of presentations to publication; publication rates ranging from 0 to $23 \%$ of presentations at the SAOC between the subspecialties were documented.

Arthroplasty has been the most active subspecialty in terms of overall research presentation comprising approximately $25 \%$ of all presentations at the SAOA congresses over the defined period. Despite this, only $7 \%$ of those presentations went on to international publication and $3 \%$ converted to local publications.

Internationally, it has been shown that the discipline least likely to achieve publication from presentations in general meetings is Trauma. ${ }^{1}$ In this series, Trauma was found to be the best performing subspecialty in terms of local publication with a $14 \%$ publication rate. Trauma also had a further $8 \%$ international publication conversion rate. Investigation of publication rates arising from subspecialtyspecific meetings in South Africa will provide important insight. Research presented at these meetings may be of a higher standard and have higher subsequent publication rates.

This study showed that presentations in the Clinical studies or Case series category had a higher conversion rate to publication than did publications in the Basic science or Biomechanical base or Audits, Educational or Miscellaneous categories. These results are in contrast to those published by Marsland et al. who noted that 
Basic sciences were more likely to progress to full publication than Clinical studies. ${ }^{2}$

There were 25 journals that published presentations from the SAOA congress. These reflected a mean average journal impact factor of 1.29. Several of these journals scored low on the Researchgate website. This compared slightly better than Daruwalla et al. from Singapore who achieved an average of 0.96 but was far lower than that found by Orr et al. from the annual general meeting for the Society of Military Orthopaedic Surgeons (SOMOS) of 2.6. ${ }^{1,4}$ There is a paucity of literature showing journal impact factors in relation to publication rates. It can be deduced however that the higher the impact factor of the journal, the greater the quality of research. ${ }^{3}$

This was the first study on record to look into publication rates of podium presentations at the SAOC. There have been several international studies in this field, and these provide a good platform from which to compare the performance of the SOAC. It also may help to outline areas of weakness that can be targeted to improve the standard of future SAOA orthopaedic meetings. This paper highlights the need for further interrogation and investigation into the various barriers to research leading to the poor rate of publication in South Africa. Future research needs to be conducted to identify specific barriers to publication, especially looking at each facet of the publication process. This will include analysing the perceived barriers as suggested above.

This study is not without limitations. Only presentations that went on to full peer-reviewed journal publication were considered. Our finding of a period of 16 months between presentation and publication is in keeping with and at the lower end of the mean time to publication of $15-25$ months noted in the literature. ${ }^{1,4,9}$ However, as presentations from 2014 and 2015 were only given three and two years respectively to allow for subsequent publication, there may be under-reporting of publications. It has been shown that publication rates peak at four years post presentation and some studies take up to ten years to reach publication. ${ }^{1}$ Future research into this field is required to establish whether time to publication in South Africa is similar to the international time periods presented above, and therefore further studies looking at publication rates need to allow for an adequate time period from presentation.

As Marsland shows, search engines may not yield all presentations that have successfully gone on to publication. ${ }^{2}$ Direct contact with each author responsible for the presentations at the annual meetings would likely yield a higher rate of publication. However, this study was modelled on research conducted in other unions in order to draw comparisons between South Africa and other influential orthopaedic communities.

Marsland et al. have also shown that several abstracts are not completed at the time of presentation, and as such, by the time they are ready for publication, the title, authorship or abstract may have required alteration. ${ }^{2}$ It has been shown that $25-30 \%$ of presentations have been altered prior to publication, and as such may not be found in the various search engines and strategies highlighted above. ${ }^{12}$ This too may have led to an underestimate of the true number of presentations that have ultimately gone on to publication.

\section{Conclusion}

There is a low conversion rate from research presented at the annual South African Orthopaedic Congress into subsequent manuscripts and eventual publication in peer-reviewed journals.

Further investigations exploring the specific barriers to publication in South Africa and comparisons of performance of the annual meeting with subspecialty meetings within the South African Orthopaedic Association will identify specific factors leading to poor publication rates and as such may provide a means for improvement.

In conclusion, this paper highlights the need for increased emphasis on publication of literature presented and support provided to facilitate publication.

\section{Ethics statement}

The study is a retrospective data analysis with no patient records analysed directly and as such no ethical clearance was needed.

\section{Declarations}

The authors declare authorship of this article and that they have followed sound scientific research practice. This research is original and does not transgress plagiarism policies.

\section{Author contributions}

$\mathrm{CH}$ : data collection, analysis and write up; JRTP: Supervisor; BMdB: data collection, analysis, submission process; DRvdJ: Supervisor; MR: Supervisor; LM: Supervisor

\section{ORCID}

Hitge C (ID https://orcid.org/0000-0002-9290-436X

Pietrzak JRT (iD http://orcid.org/0000-0001-5694-0016

De Buys BM iD https://orcid.org/0000-0002-8780-433X

Van der Jagt DR (iD) https://orcid.org/0000-0002-3301-9459

Mokete L (iD) http://orcid.org/0000-0001-9227-0515

\section{References}

1. Daruwalla ZJ, Sumon SH, Keng LW, Pei YN, Diarmuid PM. 'Publish or Perish'- presentations at annual national orthopaedic meetings and their correlation with subsequent publication, Journal of Orthopaedic Surgery and Research. 2015;10(58).

2. Marsland D, Mumith A, Taylor HP. Full text publication rates of papers presented at the British Foot and Ankle Society. Foot and Ankle Surgery. 2018;24(6):525-29.

3. Abzug JM, Osterman M, Rivlin M, Paryavi E, Osterman AL. Current rates of publication for podium and poster presentations at the American Society for Surgery of the Hand annual meetings. Archives of Bone and Joint Surgery. 2014;2(3):199-202.

4. Orr J, Dunn JC, Kusnevov N, Fares AB, Waterman BR, Garcia E, Pallis M. Publication rate and impact factor for Society of Military Orthopaedic Surgeons. Annual meeting presentations, 2009-2013. Military Medicine 2017;182:e1992-e1996.

5. Ejnisman GS, de Oliviera GR, Malavolta EA, Gobbi RG, de Camargo, P. Publication rates of papers presented at the Brazilian Orthopaedic Meeting. Acta Ortopedia Brasilia. 2013;21(5):285-87.

6. Yalcinkaya M, Bagatur E. Fate of abstracts presented at a National Turkish Orthopedics and Traumatology Congress: publication rates and consistency of abstracts compared with their subsequent full-text publications. Acta Orthopaedica et Traumatologica Turcica. 2013;47(4):223-30.

7. Voleti PB, Donegan DJ, Kim TW, Lee GC. Level of evidence: does it change the rate of publication and time to publication of American Academy of Orthopaedic Surgeons presentations? Journal of Bone and Joint Surgery (Am). 2013;95(1):e2.

8. Choudhari P, Agrawal U, Shaikh T. Trends in scientific publications of Indian arthroplasty surgeons over 15 years (2001-2015). Journal of Arthroscopy and Joint Surgery. 2017. E. pp. 94-99.

9. Donegan DJ, Kim TW, Lee GC. Publication rates of presentations at an annual meeting of the American Academy of Orthopaedic Surgery. Clinical Orthopaedics and Related Research. 2010;468(5):1428-35.

10. Schoenfeld AJ, Carey PA, Frye BD. Publication rate of presentations at an annual military orthopaedic meeting. Journal Surgery and Orthopaedic Advances. 2012;21(4):204-209.

11. Chan RKW, Lockyer J, Hutchison C. Block to succeed: the Canadian orthopaedic resident research experience. Canadian Journal of Surgery. 2009;52(3):187-95.

12. Bhandari M, Devereaux PJ, Guyatt GH, Swiontkowski MF, Sprague S, Schemitsch EH. An observational study of orthopaedic abstracts and subsequent full text publications. Journal of Bone and Joint Surgery (Am). 2002;84(A):615-21. 